\title{
Salting-Out Effects in Aqueous Ionic Liquid Solutions: Cloud-Point Temperature Shifts ${ }^{\dagger}$
}

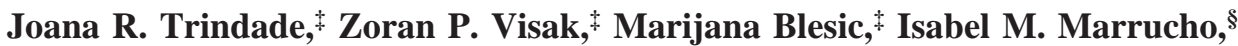 \\ João A. P. Coutinho, ${ }^{\S}$ José N. Canongia Lopes, ${ }^{*, \hbar}$ and Luis P. N. Rebelo*,‡ \\ Instituto de Tecnologia Química e Biológica, ITQB2, Universidade Nova de Lisboa, Av. República, Apartado \\ 127, 2780-901 Oeiras, Portugal, and CICECO, Departamento de Química, Universidade de Aveiro, 3810193 \\ Aveiro, Portugal
}

Received: October 26, 2006; In Final Form: December 19, 2006

\begin{abstract}
The effects of the addition of three inorganic salts, namely, $\mathrm{NaCl}, \mathrm{Na}_{2} \mathrm{SO}_{4}$, and $\mathrm{Na}_{3} \mathrm{PO}_{4}$, on the liquid-liquid $(\mathrm{L}-\mathrm{L})$ phase diagram of aqueous solutions containing the model ionic liquid 1-butyl-3-methylimidazolium tetrafluoroborate, $[\mathrm{bmim}]\left[\mathrm{BF}_{4}\right]$, were investigated. All three inorganic salts trigger salting-out effects, leading to significant upward shifts of the $\mathrm{L}-\mathrm{L}$ demixing temperatures of the systems. The magnitude of the shifts depends on both the water-structuring nature of the salt and its concentration; that is, the effects are correlated with the ionic strength of the solution and the Gibbs free energy of hydration of the inorganic salt. The $\mathrm{pH}$ effect and the occurrence of salt precipitation in concentrated solutions are also discussed.
\end{abstract}

\section{Introduction}

The recent years have witnessed the growing relevance of ionic liquids. Stimulating and surprising discoveries-which underlay the unique, complex nature of these salts seen as composed of polar and nonpolar domains ${ }^{1}$-were recently reported, for instance, (i) the separation of two ionic liquids by either low-pressure, moderate temperature distillation ${ }^{2}$ or (ii) simple low-temperature liquid-liquid phase splitting, ${ }^{3}$ (iii) demixing phenomena of ionic liquid solutions by temperature increase, ${ }^{4}$ (iv) the formation of liquid clathrates and inclusion crystals in their mixtures with other solvents, ${ }^{5,6}$ and (v) the cascade of phase changes as switching (compositional) devices ${ }^{7,8}$ in ionic liquid solutions triggered by the interplay between the water/alcohol cosolvent effect and the $\mathrm{CO}_{2}$ anti-solvent outcome.

In another very interesting study, Gutowski et al. ${ }^{9}$ demonstrated that it is possible to form aqueous biphasic systems (ABS), that is, to provoke the coexistence of two immiscible aqueous phases, using a water-soluble ionic liquid and a waterstructuring inorganic salt. In their study, they used aqueous solutions of 1-butyl-3-methylimidazolium chloride, [bmim] Cl(aq), and a concentrated solution of potassium phosphate, $\mathrm{K}_{3}$ $\mathrm{PO}_{4}(\mathrm{aq})$. Salting-out effects involving ionic liquid aqueous solutions were also briefly reported by Dupont et al. ${ }^{10} \mathrm{At}$ room temperature, and by adding potassium chloride $(\mathrm{KCl})$, they witnessed the appearance of two phases in (water + 1-butyl3-methylimidazolium tetrafluoroborate, $\left.[\mathrm{bmim}]\left[\mathrm{BF}_{4}\right]\right)$ mixtures, a binary system that is homogeneous under ambient conditions at all proportions of the constituents. Unfortunately, no quantitative data were reported.

While Gutowski et al. ${ }^{9}$ investigated the phenomenon at constant, room temperature, we are interested in studying the temperature dependence of the formed demixing loci upon addition of the inorganic salt (water + ionic liquid + inorganic salt), specifically, either the appearance of an upper critical

\footnotetext{
Part of the special issue "Physical Chemistry of Ionic Liquids".

* To whom correspondence should be addressed. E-mail: jnlopes@ist.utl.pt (J.N.C.L.); luis.rebelo@itqb.unl.pt (L.P.N.R.).

$¥$ Universidade Nova de Lisboa.

\& Universidade de Aveiro.
}

solution temperature (UCST) or the increase of the heterogeneous temperature-composition domain in these pseudobinary mixtures as compared with their strictly binary counterparts of (water + ionic liquid) mixtures.

Liquid-liquid critical behavior has been found for ionic liquids in either water or alcohols, ${ }^{7,11,12}$ chloroalkanes, ${ }^{4}$ and aromatic $^{6}$ and aliphatic ${ }^{13}$ alkanes. Recently, we reported a thorough case study ${ }^{12}$ on aqueous solutions of $\left[\mathrm{bmim}^{2}\left[\mathrm{BF}_{4}\right]\right.$ aimed at modeling ionic liquid aqueous solutions. The current work constitutes a natural extension of that detailed research. This ionic liquid, though potentially harmful ${ }^{14}$ as all the hexafluorophosphate, $\left[\mathrm{PF}_{6}\right]^{-}$, -based ionic liquids, has been comprehensively investigated as a model ionic liquid and has an advantage over, for example, its $\left[\mathrm{bmim}^{\mathrm{m}}\right]\left[\mathrm{PF}_{6}\right]$ partner, for any proportion of its solutions with water can be investigated at convenient working temperatures, both in the totally homogeneous region (above $\sim 278 \mathrm{~K}$ ) and in the partially miscible one (below $\sim 278 \mathrm{~K}$ ).

In the current work, the effects of three inorganic salts, $\mathrm{NaCl}$, $\mathrm{Na}_{2} \mathrm{SO}_{4}$, and $\mathrm{Na}_{3} \mathrm{PO}_{4}$, on the phase fluid behavior of aqueous solutions of $[\mathrm{bmim}]\left[\mathrm{BF}_{4}\right]$ are analyzed. We investigated the temperature dependence of the demixing process, via cloudpoint temperature determinations, as a function of the waterstructuring strength of the inorganic salts and the composition of the solutions. The influence of $\mathrm{pH}$ is also discussed. At high ionic concentrations, precipitation of the inorganic salt precludes the complete development of the liquid-liquid consolute curve.

\section{Experimental Section}

2.1. Chemicals and Preparation of Solutions. The ionic liquid 1-butyl-3-methylimidazolium, $\left[\mathrm{C}_{4} \mathrm{mim}\right]\left[\mathrm{BF}_{4}\right]$, was purchased from Solvent Innovation (stated purity $>98 \mathrm{w} / \mathrm{w} \%$ ), Germany. It underwent further purification stages and analytical checks identical to those previously reported. ${ }^{2}$ In order to reduce the water content-although not an important issue in the current study of aqueous solutions - and volatile compounds to negligible values, vacuum $(0.1 \mathrm{~Pa})$ and moderate temperature $\left(60{ }^{\circ} \mathrm{C}\right)$ were applied to several samples of $[\mathrm{bmim}]\left[\mathrm{BF}_{4}\right]$ for typically 2 days always immediately prior to their use. Untreated, 

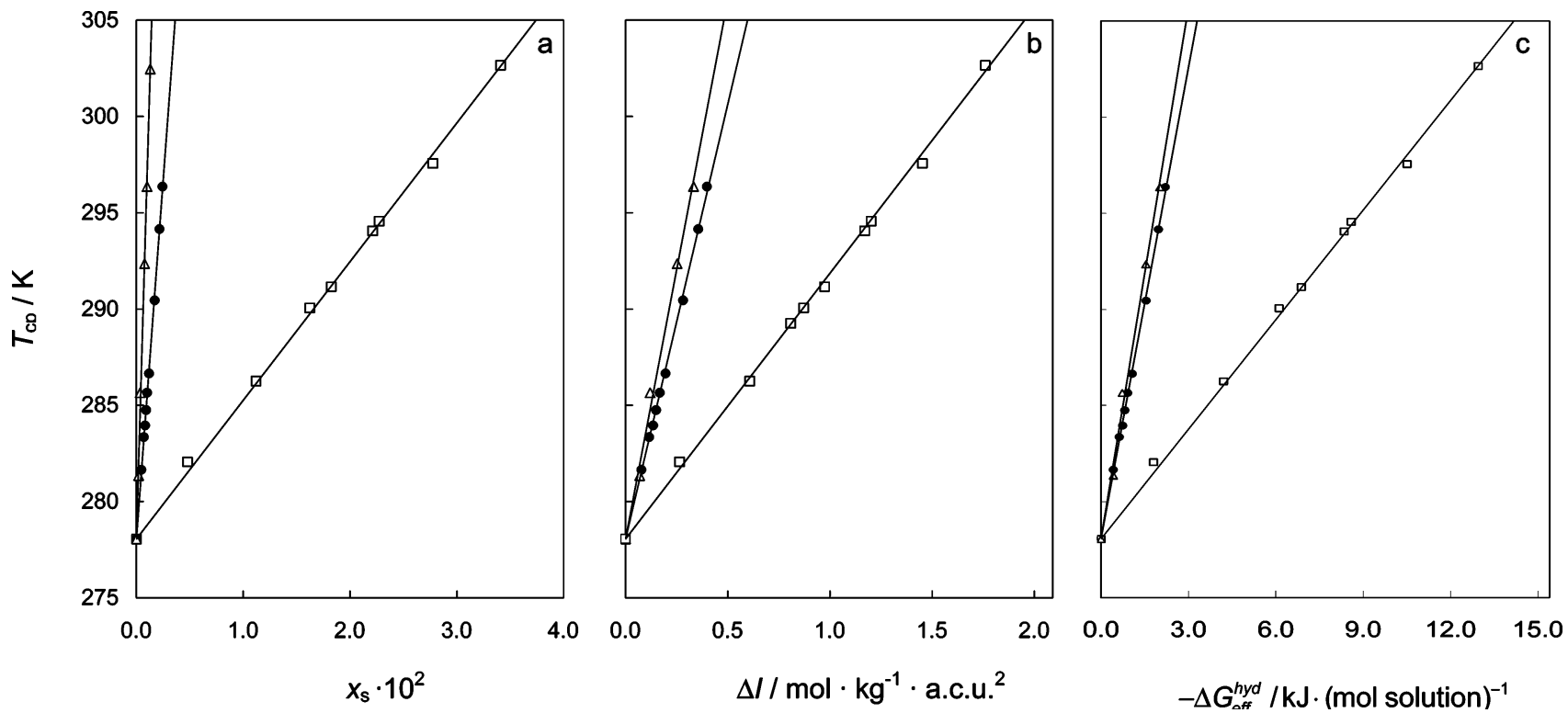

Figure 1. Cloud-point temperatures of ([bmim] $\left[\mathrm{BF}_{4}\right]+\mathrm{H}_{2} \mathrm{O}+$ inorganic salt) solutions as a function of the (a) mole fraction of inorganic salt $\left(x_{\mathrm{s}}\right)$ in the $\left(\mathrm{H}_{2} \mathrm{O}+\right.$ inorganic salt) solution, (b) ionic strength increase $(\Delta I)$ of the solution, and (c) effective Gibbs energy of hydration of the solution. $\square, \mathrm{NaCl} ; \bullet, \mathrm{Na}_{2} \mathrm{SO}_{4} ; \Delta, \mathrm{Na}_{3} \mathrm{PO}_{4}$.

original samples revealed 3900-4300 ppm of water, while those undergoing drying showed $70 \pm 10 \mathrm{ppm}$ (coulometric "Aquapal" Karl Fischer). The $\mathrm{Cl}^{-}$content is in the range 80-130 ppm (Dionex HPLC anion exchange chromatography $=121 \pm$ 7 ppm; photometric detection of the unreacted excess of iron thyocyanate(III) after the addition of mercury thyocyanate(II) and an iron salt $=84 \mathrm{ppm} ; \mathrm{Cl}^{-}$specific electrode using the standard addition method $=100 \pm 20 \mathrm{ppm}$ ). ESI-MS (in methanol; dilution $1: 1000$, source temperature $150^{\circ} \mathrm{C}$ ) in the positive and negative modes revealed the expected complexes of the general form $\left\{[\mathrm{bmim}]_{x}\left[\mathrm{BF}_{4}\right]_{y}\right\}^{x-y}$, thus no impurities within the limit of detection of $\sim 0.3 \mathrm{~mol} \%$.

The inorganic salts, sodium chloride $(\mathrm{NaCl}$, Sigma Aldrich, 99.5 w/w \%), sodium sulfate $\left(\mathrm{Na}_{2} \mathrm{SO}_{4}\right.$, Fluka and Fluka, 99 w/w $\%)$, and sodium phosphate $\left(\mathrm{Na}_{3} \mathrm{PO}_{4}\right.$, Riedel-de-Haën, 96 w/w $\%)$, were used as received, without further purification. Normal water was doubly distilled and deionized (Millipore Co. equipment, Bedford, MA).

All solutions were gravimetrically prepared with an estimated weight fraction uncertainty of $\pm 2 \times 10^{-5}$. Due to the relatively chemical instability of $\left[\mathrm{C}_{4} \mathrm{mim}\right]\left[\mathrm{BF}_{4}\right]$ with respect to its hydrolosis, ${ }^{14}$ we have always used fresh solutions for each experimental run-the ionic liquid has never been recycled. The potential decomposition - a very slow process at room temperatureis accelerated as the temperature rises, and therefore, experiments at higher temperatures (which, nevertheless, have never exceeded the moderate temperature of $325 \mathrm{~K}$ ) were designed to be performed as quickly as possible. In contrast with situations in which we have forced hydrolysis to occur, in the current work, we have never witnessed "foggy" glass capillary walls due to the attack of HF and we also were always able to reproduce the same experimental result whenever re-examined.

2.2. Experimental Procedure. The loci of the onset of liquid-liquid immiscibility (cloud points) were determined at a nominal pressure of $0.1 \mathrm{MPa}$ using visual detection of the phase demixing (naked eye observation of turbidity followed by phase separation). Samples of the solutions were encapsulated in bottom-sealed, top-narrow-necked Pyrex-glass capillaries with a stirrer inside. The solutions were then frozen under vacuum and the capillaries sealed at the narrow neck of the open end. On warming and melting, the liquid inside the capillary always occupied almost its entire internal volume $\left( \pm 0.5 \mathrm{~cm}^{3}\right)$, allowing only for a small dead volume of vapor phase. The capillaries were placed in a glass thermostat beaker of $2 \mathrm{~L}$ filled with ethanol (from 253-293 K) or water (from 293-333 K) as the thermostatic fluid. The solutions were cooled off or heated with continuous stirring, and the process was performed in three to four runs with the last run being carried out very slowly (the rate of temperature change near the cloud point was no more than $5 \mathrm{~K} \cdot \mathrm{h}^{-1}$, except in those runs performed at moderately high temperatures (vide supra). Beginning in the two-phase region, upon heating, the temperature at which the last sign of turbidity disappeared was taken as the temperature of the liquid-liquid phase transition. Conversely, beginning in the homogeneous region, upon cooling, the temperature at which the first sign of turbidity appeared was taken as the temperature of the liquidliquid phase transition. Temperature was monitored using a fourwire platinum resistance thermometer coupled to a Keithley 199 System DMM/Scanner. The thermometer was calibrated against high-accuracy mercury thermometers $( \pm 0.01 \mathrm{~K})$.

Auxiliary pH determinations (ORION, model 420A, coupled with a Metrohm combined electrode) were performed at room temperature under one-phase conditions (see Supporting Information Tables S2-S4).

\section{Results and Discussion}

In the first set of experiments, the inorganic salts, $\mathrm{NaCl}, \mathrm{Na}_{2}-$ $\mathrm{SO}_{4}$, and $\mathrm{Na}_{3} \mathrm{PO}_{4}$, were added to a (ionic liquid + water) binary mixture with a near-critical composition ${ }^{12}\left(w_{\mathrm{IL}}=0.498\right.$ or $x_{\mathrm{IL}}$ $=0.0732$, where $w_{\mathrm{IL}}$ and $x_{\mathrm{IL}}$ stand for the weight and molar fractions of ionic liquid, respectively). Significant positive shifts in the transition temperatures were observed for all systems. These results are presented in parts $\mathrm{a}-\mathrm{c}$ of Figure 1, respectively, as a function of the inorganic salt content, the concomitant increase of the ionic strength $(\Delta I)$ of the solution, and the effective Gibbs free energies of hydration $\left(\Delta G_{\text {eff }}^{\text {hyd }}\right)$ of the inorganic salt ions. The latter two quantities were calculated, respectively, using the following equations:

$$
\Delta I=\sum_{i} m_{i} z_{i}^{2}
$$




$$
\Delta G_{\mathrm{eff}}^{\mathrm{hyd}}=\frac{1}{n_{\mathrm{T}}} \sum n_{i} g_{i}^{\mathrm{hyd}}
$$

in which $m_{i}$ represents the molal concentration of each inorganic salt ion in the aqueous solution, $z_{i}$ is its formal charge, $n_{i}$ and $n_{\mathrm{T}}$ are the number of moles of each inorganic salt ion and of the ternary mixture (total), respectively, and $g_{i}^{\text {hyd }}$ are the published molar Gibbs free energies of hydration for different ion species, ${ }^{15}$ at $298.15 \mathrm{~K}$. The latter were used for the calculations at other temperatures as well, since the molar entropies of hydration of the studied inorganic salt ions at 298.15 $\mathrm{K}$ are low, ${ }^{16}$ thus reflecting the weak temperature dependence of the molar Gibbs energies of hydration (the largest correction would be less than $0.5 \%$ ).

The $g_{i}^{\text {hyd }}$ value of an ion, $\mathrm{A}^{\circ}$, is defined as the Gibbs energy of the process $\mathrm{A}^{\circ}(\mathrm{g}) \rightarrow \mathrm{A}^{\circ}(\mathrm{aq}) .{ }^{17}$ The values of $m_{i}$ and $n_{i}$ were calculated taking into account the $\mathrm{pH}$ values of each solution (see Supporting Information Table S1). In the case of solutions containing $\mathrm{Na}_{2} \mathrm{SO}_{4}, \mathrm{pH}$ values in the range 6.2-6.8 indicate that these salts are completely dissociated in aqueous solution. As for $\mathrm{Na}_{3} \mathrm{PO}_{4}, \mathrm{pH}$ values above 10 imply that the equilibrium between the $\mathrm{PO}_{4}{ }^{3-}$ and $\mathrm{HPO}_{4}{ }^{2-}$ anions has to be considered: $\mathrm{PO}_{4}{ }^{3-}+\mathrm{H}_{2} \mathrm{O} \rightleftarrows \mathrm{HPO}_{4}{ }^{2-}+\mathrm{OH}^{-}\left(K_{\mathrm{b}}=2.24 \times 10^{-2}\right.$; the other two hydrolysis reactions can be neglected). The experimental $\mathrm{pH}$ values of the ternary solutions were used to calculate the quantities of each ion $\left(\mathrm{PO}_{4}{ }^{3-}, \mathrm{HPO}_{4}{ }^{2-}\right.$, and $\left.\mathrm{OH}^{-}\right)$in solution. ${ }^{1} \mathrm{H}$ NMR analyses showed that even at these high $\mathrm{pH}$ values the imidazolium ring of the ionic liquid did not lose its acidic proton, which means that the nature of the IL + water solution remains the same; see the Supporting Information.

Figure 1a shows that the temperature shifts are directly proportional to the added amount of inorganic salt. In the present case, all temperature shifts correspond to salting-out effects (decreasing miscibility; in other words, shifting upward the consolute liquid-liquid curve). The magnitude increases in the order $\mathrm{NaCl}<\mathrm{Na}_{2} \mathrm{SO}_{4}<\mathrm{Na}_{3} \mathrm{PO}_{4}$.

The effect of the addition of salts on the miscibility of a given solute (in the present case also ionic in nature) in an aqueous solution is very complex, primarily because a large number of different types of intermolecular interactions come into play between the added ions and the solvent, the added ions and the solute ions, and the solute ions and the solvent. When this is kept in mind, it is not surprising that various theories, stressing the importance of different interactions, have been proposed to explain the mechanisms of salting out. ${ }^{16}$ Some of the most common theories involve the concepts of structure-forming (kosmotropic) salts that promote a water-structuring effect around them. These theories are also known under the label of hydration theories.

When a salt is dissolved in an aqueous solution, its ions are surrounded by a layer of water molecules, a process known as ionic hydration. Those water molecules are immobilized (hence the adjectives water-structuring or kosmotropic), and their role as solvents to other molecules or ions is reduced. In the present case, when an inorganic salt is added to a solution of an ionic liquid, they compete with each other for the solvent molecules. The competition is won by the inorganic ions (with a stronger affinity for the solvent), and those of the ionic liquid lose. There is a "migration" of solvent molecules away from the ions of the ionic liquid to those of the inorganic salt, which, in turn, decreases the hydration and hence the solubility of the ions of the ionic liquid. As a consequence, a phase rich in ionic liquid separates from the rest of the solution. This means that the salting-out effect must be directly correlated to the hydration strength of the different ions of the inorganic salt.
Figure $1 \mathrm{~b}$ and $\mathrm{c}$ shows that the cloud-point temperature shifts are indeed correlated with the ionic strength of the solution and the effective Gibbs free energies of hydration of the anions and cations of the inorganic salt. However, the hydration/kosmotropic effect cannot alone account for the whole salting-out effect in this case: as one moves from Figure 1a to Figure 1c, the lines depicting the shifts for the three salts come closer but do not superimpose in Figure 1c, as one would expect if the saltingout effect was caused solely by the different Gibbs free energies of hydration of the ions that constitute the three inorganic salts under analysis.

An explanation for this fact can be obtained from a second set of experiments where the temperature-composition phase diagrams of aqueous solutions of $[\mathrm{bmim}]\left[\mathrm{BF}_{4}\right]$ for several fixed concentrations of inorganic salt in water were determined. The results are presented in Figure 2. The same trend, that is, an increasing salting-out effect from $\mathrm{NaCl}$ to $\mathrm{Na}_{3} \mathrm{PO}_{4}$, can be surmised from the comparison of the three graphs. Figure 3 plots explicitly such an effect by showing the salting-out effects at invariant inorganic salt concentration.

Still, the diagrams depicted in Figures 2 and 3 also show that the shapes of the immiscibility windows (cloud-point temperature envelopes) for the three (IL + water + inorganic salt) systems are strikingly different. These differences can be explained if we take into account the different solubilities of the three inorganic salts in water.

The first point to consider is that $\mathrm{NaCl}$ is much more soluble in water than $\mathrm{Na}_{2} \mathrm{SO}_{4}$ or $\mathrm{Na}_{3} \mathrm{PO}_{4}(9.9,2.5$, and $0.6 \mathrm{~mol} \%$, respectively). Second, for the studied solutions with higher $\mathrm{Na}_{2}-$ $\mathrm{SO}_{4}$ or $\mathrm{Na}_{3} \mathrm{PO}_{4}$ content, once the quantity of the IL present in the ternary mixture exceeds a given threshold value, the inorganic salts start to precipitate. In other words, the presence of another salt (the ionic liquid) makes the solubility of $\mathrm{Na}_{2}-$ $\mathrm{SO}_{4}$ and $\mathrm{Na}_{3} \mathrm{PO}_{4}$ in aqueous $\left[\right.$ bmim] $\left[\mathrm{BF}_{4}\right]$ solutions lower than that of these salts in pure water. This is also a salting-out effect: when it was stated above that, in the competition between the inorganic salt and the ionic liquid for the water molecules the former wins and the latter loses, it was never assumed that the victory was absolute-some of the ionic liquid rich phase (the loser side) will carry with it some water molecules. This will promote the precipitation of the inorganic salt in the more concentrated solutions.

In a more quantitative perspective, the Setschenow-type equation, ${ }^{18} \log \left(s_{0} / s\right)=k c_{\mathrm{s}}$, states that the solubility of a given solute in aqueous solution shifts from $s_{0}$ to $s$ in the presence of an added amount of salt of concentration $c_{\mathrm{s}}$. The salting constant can be either positive or negative, denoting a salting-out or salting-in effect, respectively.

Since this precipitation is very slow, the related liquid-solid equilibrium lines could not be determined quantitatively, as it was difficult to detect exactly when the precipitation had begun, but only that the solid phase dissolved as the temperature increased. The dashed vertical lines that cut the corresponding phase diagrams in Figures 2 and 3 only give a rough indication of the last points of $\mathrm{L}-\mathrm{L}$ demixing observed without precipitation. In the case of all three inorganic salts, the absence of precipitation at the cloud-point temperature was verified by keeping the respective samples at a temperature slightly lower than the lowest cloud point detected $\left(20{ }^{\circ} \mathrm{C}\right.$ for $\mathrm{Na}_{3} \mathrm{PO}_{4}$ and $\mathrm{Na}_{2} \mathrm{SO}_{4} ; 0{ }^{\circ} \mathrm{C}$ for $\mathrm{NaCl}$ ), for a period of $24 \mathrm{~h}$. However, in the case of $\mathrm{NaCl}$, no precipitation was observed for all of the involved quantities of the inorganic salt.

The existence of this "cross" salting-out effect for solutions of $\mathrm{Na}_{2} \mathrm{SO}_{4}$ and $\mathrm{Na}_{3} \mathrm{PO}_{4}$ can help explain the trend observed in 

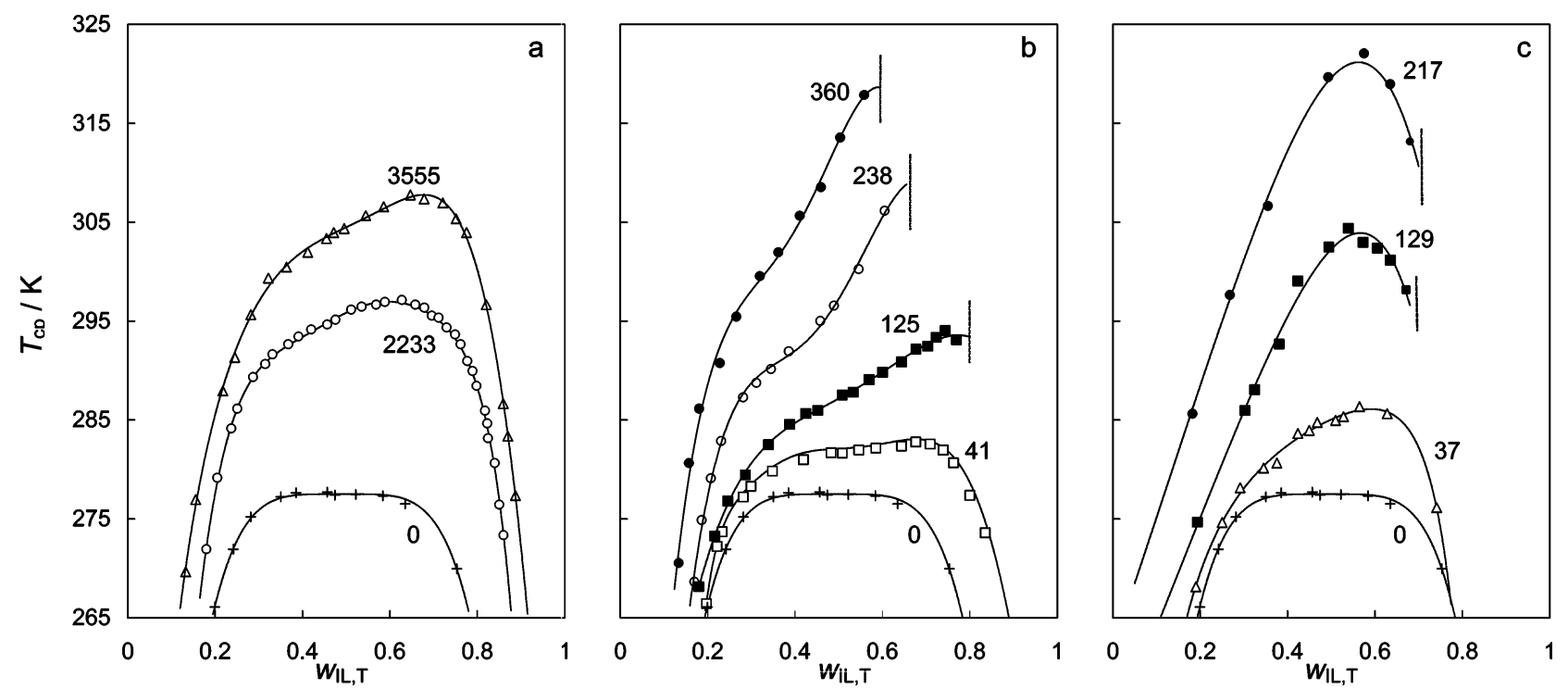

Figure 2. Temperature-composition phase diagrams of ([bmim] $\left[\mathrm{BF}_{4}\right]+\mathrm{H}_{2} \mathrm{O}+$ inorganic salt) solutions as a function of the weight fraction of ionic liquid in the ternary solution ( $w_{\mathrm{IL}, \mathrm{T}}$ ): (a) $\mathrm{NaCl}$; (b) $\mathrm{Na}_{2} \mathrm{SO}_{4}$; (c) $\mathrm{Na}_{3} \mathrm{PO}_{4}$. The numbers labeling each curve represent $10^{5}$ times the mole fraction of inorganic salt in the $\left(\mathrm{H}_{2} \mathrm{O}+\right.$ inorganic salt) solution. All solid lines were drawn as visual aids, except for solutions without inorganic salt in which case they were calculated using a scaling equation. ${ }^{12}$ The dashed vertical lines mark the last cloud points obtained without inorganic salt precipitation.

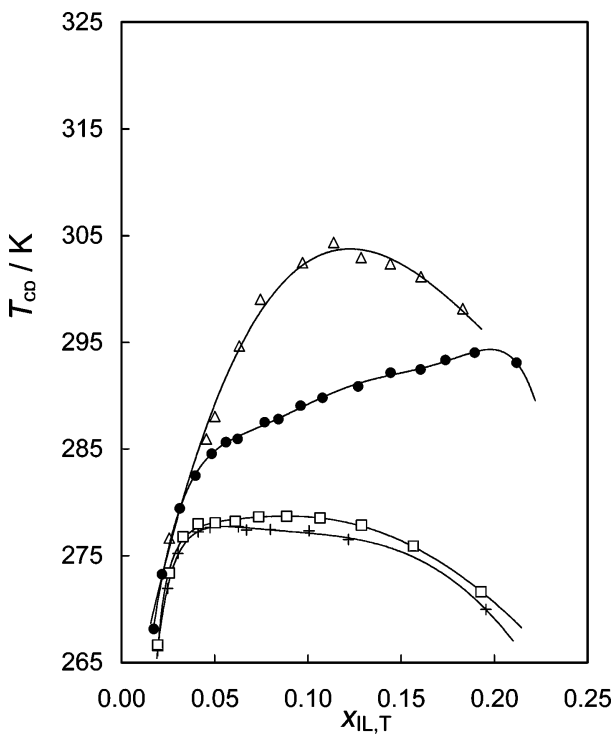

Figure 3. Temperature-composition phase diagrams for solutions of ([bmim $]\left[\mathrm{BF}_{4}\right]+\mathrm{H}_{2} \mathrm{O}+$ inorganic salt) with the same inorganic-saltto-water ratio (approximately $125 \times 10^{-5}$ ) as a function of the mole fraction of ionic liquid in the ternary solution $\left(x_{\mathrm{IL}, \mathrm{T}}\right): \square, \mathrm{NaCl} ; \bullet, \mathrm{Na}_{2}$ $\mathrm{SO}_{4} ; \Delta, \mathrm{Na}_{3} \mathrm{PO}_{4} ;+$, no inorganic salt. In the case of $\mathrm{NaCl}$, the points were obtained by interpolation. All lines are drawn as visual aids.

the first set of experiments (Figure 1c) where the cloud-point temperature shifts and the free energies of hydration of the solutions are not completely correlated for the three studied salts (there are only correlations for each individual salt). The different shapes of the immiscibility envelope for each type of system indicates the presence of another process that can cause demixing of the solution, that is, the precipitation of the inorganic salt itself. In Figure 1, we are representing a section of those envelopes at a fixed ionic liquid composition. These correspond to different phase behaviors of the systems: the salting-out effect that promotes the separation of the phase rich in the ionic liquid, which is stronger as one goes from $\mathrm{NaCl}$ to $\mathrm{Na}_{2} \mathrm{SO}_{4}$ and to $\mathrm{Na}_{3} \mathrm{PO}_{4}$, has to be added to the "cross" saltingout effect that promotes the precipitation of these last two salts. This means that in the case of systems containing $\mathrm{Na}_{2} \mathrm{SO}_{4}$ and
$\mathrm{Na}_{3} \mathrm{PO}_{4}$ the positive shifts in the cloud-point temperature are even higher than those predicted by a purely kosmotropic or Gibbs free energy of hydration effect.

Finally, it is worth mentioning that although we have attempted to provoke phase separation in the well-known totally miscible $([\mathrm{bmim}] \mathrm{Cl}+$ water $)$ system by adding increasing amounts of $\mathrm{NaCl}$, no phase splitting was observed. Despite the reasoning that one should expect greater salting-out effects whenever a common precipitating ion is present ("common ion effect"), due to a change in the entropic contributions, the aforementioned absence of heterogeneity simply means that $\mathrm{NaCl}$ provokes weak salting-out effects as opposed to, for example, $\mathrm{K}_{3} \mathrm{PO}_{4}$ with which Rogers and co-workers ${ }^{9}$ found phase splitting occurring in the $([\mathrm{bmim}] \mathrm{Cl}+$ water $)$ system.

\section{Conclusions}

Salting-out effects in solutions containing ionic liquids and the possibility of formation of aqueous biphasic systems ${ }^{9,19-a}$ direct consequence of the fact that the salted-out salt is a liquid at room temperature and will carry with it a relatively large amount of solvent molecules-open new areas of research and development in domains as diverse as separation technology, biphasic catalysis, or biotechnology (see ref 19 and references therein)

The mechanisms of the salting-out effects are complex due to the interplay of different types of interaction between the solutes (ions from the inorganic salt and ionic liquid) and the solvent. Hydration theories and the related water-structuring effects (kosmotropy) can explain in a simple, semiquantitative way the intensity of the salting-out effects. However, the complicated structure of water and aqueous solutions (including those near the saturation limit of a given salt) and the dual nature of the interactions of the ions of the ionic liquids (in particular bulky cations with a more or less important hydrophobic aliphatic side chain) will introduce perturbations to the general trends that will always be hard to model or quantify and warrant further studies on this subject.

Acknowledgment. The authors wish to thank Professor Yitzak Marcus, Hebrew University of Jerusalem, Israel, for 
sharing data. We are also grateful to several colleagues from ITQB, Oeiras, Portugal: Professor Rita Delgado, Dr. António Lopes, and Krassimira Guerra for providing the equipment for the $\mathrm{pH}$ measurements as well as Dr. Helena Matias for performing the NMR analysis. Z.P.V. and M.B. are grateful to FC\&T, Portugal, for a post-doc and a Ph.D. grant, respectively. This work was financially supported by FC\&T, Portugal, through grant nos. POCI/QUI/ 57716/2004 and POCI/EQU/ $58152 / 2004$.

Supporting Information Available: ${ }^{1} \mathrm{H}$ NMR spectrum of aqueous $\left[\mathrm{C}_{4} \mathrm{mim}\right]\left[\mathrm{BF}_{4}\right]$ in the presence of $\mathrm{Na}_{3} \mathrm{PO}_{4}$ (basic $\mathrm{pH}$ ) and tabulated data of the experimental phase diagrams. This material is available free of charge via the Internet at http:// pubs.acs.org.

\section{References and Notes}

(1) (a) Wang, Y.; Voth, G. A. J. Am. Chem. Soc. 2005, 127, 12192 (b) Pádua, A. A. H.; Canongia Lopes, J. N. J. Phys. Chem. B 2006, 110, 3330. (c) Canongia Lopes, J. N.; Costa Gomes, M. F.; Pádua, A. A. H. J. Phys. Chem. B 2006, 110, 16816.

(2) (a) Earle, M. J.; Esperança, J. M. S. S.; Gilea, M. A.; Canongia Lopes, J. N.; Rebelo, L. P. N.; Magee, J. W.; Seddon, K. R.; Widegren, J. A. Nature 2006, 439, 831. (b) Rebelo, L. P. N.; Canongia Lopes, J. N.; Esperança, J. M. S. S.; Filipe, E. J. Phys. Chem. B 2005, 109, 6040. (c) Wasserscheid, P. Nature 2006, 439, 797.

(3) Arce, A.; Earle, M. J.; Katdare, S. P.; Rodríguez, H.; Seddon, K. R. Chem. Commun. 2006, 2548-2550.

(4) (a) Iachwa, J.; Szydlowski, J.; Najdanovic-Visak, V.; Rebelo, L. P. N.; Seddon, K. R.; Nunes da Ponte, M.; Esperança, J. M. S. S.; Guedes, H. J. R. J. Am. Chem. Soc. 2005, 127, 6542. (b) Wiegand, S.; Kleemeier, M.; Schröder, J.-M.; Schöer, W.; Weingärtner, H. Int. J. Thermophys. 1994 $15,1045$.

(5) (a) Holbrey, J. D.; Reichert, W. M.; Nieuwenhuyzen, M.; Sheppard, O.; Hardacre, C.; Rogers, R. D. Chem. Commun. 2003, 476. (b) Deetlefs, M.; Hardacre, C.; Nieuwenhuyzen, M.; Sheppard, O.; Soper, A. K. J. Phys. Chem. B 2005, 109, 1593.

(6) (a) Łachwa, J.; Szydlowski, J.; Makowska, A.; Seddon, K. R.; Esperança, J. M. S. S.; Guedes, H. J. R.; Rebelo, L. P. N. Green Chem. 2006, 8, 262. (b) Jachwa, J.; Bento, I.; Duarte, M. T.; Lopes, J. N. C.; Rebelo, L. P. N. Chem. Commun. 2006, 2445.

(7) (a) Swatloski, R. P.; Visser, A. E.; Reichhert, W. M.; Broker, G. A.; Farina, L. M.; Holbrey J. D.; Rogers, R. D. Chem. Commun. 2001, 2070. (b) Najdanovic-Visak, V.; Esperança, J. M. S. S.; Rebelo, L. P. N.; Nunes, da Ponte, M.; Guedes, H. J. R.; Seddon, K. R.; de Sousa, H. C.; Szydlowski, J. Phys. Chem. Chem. Phys. 2002, 4, 1701. (c) NajdanovicVisak, V.; Esperança, J. M. S. S.; Rebelo, L. P. N.; Nunes da Ponte, M.;
Guedes, H. J. R.; Seddon, K. R.; de Sousa, H. C.; Szydlowski, J. J. Phys. Chem B 2003, 107, 12797.

(8) (a) Najdanovic-Visak, V.; Serbanovic, A.; Esperanca, J. M. S. S.; Guedes, H. J. R.; Rebelo, L. P. N.; Nunes da Ponte, M. ChemPhysChem 2003, 4, 520. (b) Blanchard, L. A.; Hancu, D.; Beckman, E. J.; Brennecke, J. F. Nature 1999, 399, 28. (c) Blanchard, L. A.; Brennecke, J. F. Ind. Eng. Chem. Res. 2001, 40, 287. (d) Scurto, A. M.; Aki, S. N. V. K.; Brennecke, J. F. J. Am. Chem. Soc. 2002, 124, 10276.

(9) Gutowski, K. E.; Broker, G. A.; Willauer, H. D.; Huddelston, J. G.; Swatloski, R. P.; Holbrey, J. D.; Rogers, R. D. J. Am. Chem. Soc. 2003, 125,6632 .

(10) Dupont, J.; Consorti, C. S.; Suarez, P. A. Z.; de Souza, R. F. In Organic Syntheses; Hegedus, L. S., Ed.; John Wiley: Chichester, U.K., 2002; Vol. 79, p 236.

(11) (a) Wagner, M.; Stanga, O.; Schröer, W. Phys. Chem. Chem. Phys. 2003, 5, 3943. (b) Dullius, J. E. L.; Suarez, P. A. Z.; Einloft, S.; de Souza R. F.; Dupont, J.; Fisher, J.; Cian, A. D. Organometallics 1998, 17, 815. (c) Crosthwaite, J. M.; Aki, S. N. V. K.; Maginn, E. J.; Brennecke, J. F. J. Phys. Chem. B 2004, 108, 5113. (d) Wagner, M.; Stanga, O.; Schröer, W. Phys. Chem. Chem. Phys. 2003, 5, 3943. (e) Wagner, M.; Stanga, O.; Schröer, W. Phys. Chem. Chem. Phys. 2004, 6, 4421. (f) Wu, C.-T.; Marsh, K. N.; Deev, A. V.; Boxall, J. A. J. Chem. Eng. Data 2003, 48, 486. (g) Marsh, K. N.; Deev, A. V.; Wu, C.-T.; Tran, E.; Klamt, A. Korean J. Chem. Eng. 2002, 19, 357. (h) Heintz, A.; Lehmann, J. K.; Wertz, C. J. Chem. Eng. Data 2003, 48, 472. (i) Swatloski, R. P.; Visser, A. E.; Reichhert, W. M.; Broker, G. A.; Farina, L. M.; Holbrey, J. D.; Rogers, R. D. Green Chem. 2002, 4, 81. (j) Döker, M.; Gmehling, J. Fluid Phase Equilib. 2005, 227, 255. (k) Domanska, U.; Pobudkowska, A.; Eckert, F. J. Chem. Thermodyn. 2006, 38, 685. (1) Domanska, U.; Pobudkowska, A.; Wisniewska, A. J. Solution Chem. 2006, 35, 311. (m) Schöer, W.; Wiegand, S.; Kleemeier, M.; Weingärtner, H. J. Phys.: Condens. Matter 1994, 6, A157. (n) Kleemeier, M.; Schöer, W.; Weingärtner, H. J. Mol. Liq. 1997, 73-74, 501 .

(12) Rebelo, L. P. N.; Najdanovic-Visak, V.; Visak, Z. P.; Nunes da Ponte, M.; Szydlowski, J.; Cerdeiriña, C. A.; Troncoso, J.; Romani, L. Green Chem. 2004, 6, 369.

(13) (a) Domanska, U.; Pobudkowska, A.; Eckert, F. Green Chem. 2006 8, 268. (b) Saracsan, D.; Rybarsch, C.; Schröer, W. Z. Phys. Chem. 2006, $10,1417$.

(14) (a) Swatloski, R. P.; Holbrey, J. D.; Rogers, R. D. Green Chem. 2003, 5, 361. (b) Visser, A. E.; Swatloski, R. P.; Reichert, W. M.; Griffin, S. T.; Rogers, R. D. Ind. Eng. Chem. Res. 2000, 39, 3596.

(15) (a) Fawcett, R. W. J. Phys. Chem. B 1999, 103, 11181. (b) Marcus, Y. J. Chem. Soc., Faraday Trans. 1991, 87, 2995.

(16) (a) Marcus, Y.; Loewenschuss, A. Annu. Rep. C 1984, 1985, 81. (b) Marcus, Y. J. Chem. Soc., Faraday Trans. 1 1986, 82, 233.

(17) Marcus, Y. J. Chem. Soc., Faraday Trans. 1987, 83, 2985.

(18) Grover, P. K.; Ryall, R. L. Chem. Rev. 2005, 105, 1.

(19) Abraham, M. H.; Zissimos, A. M.; Huddleston, J. G.; Willauer, H. D.; Rogers, R. D.; Acree, W. E., Jr. Ind. Eng. Chem. Res. 2003, 42, 413. 